SECTION 6. Metallurgy and energy.

Bazartai Alimbayevich Alimbayev doctor of technical sciences,

Professor of the department «Building materials and constructions»

M.Kh. Dulaty Taraz State University, Kazakhstan

Bauyrzhan Zharkynbekovich Manapbayev candidate of technical sciences, associate professor of the Department of «Oil and gas engineering »

M.Kh. Dulaty Taraz State University, Kazakhstan jiboj@mail.ru

Zhanna Bazartayevna Alimbayeva Senior lecturer of the department « Architecture and construction production » M.Kh. Dulaty Taraz State University, Kazakhstan

Olzhas Ongarovich Kozhas, student of the Department of Oil and gas engineering M.Kh. Dulaty Taraz State University, Kazakhstan

Diana Bekbosynovna Rysbai student of the Department of Oil and gas engineering M.Kh. Dulaty Taraz State University, Kazakhstan

\title{
ABOUT ONE WAY OF DRAWING OF THE ANTICORROSIVE COVERING ON THE INTERNAL SURFACE OF PIPES
}

\begin{abstract}
The paper presents a brief analysis of the methods of applying anticorrosion coatings for metals and provides a method of anticorrosive coating on the inner surface of the pipe based on the ferromagnetic properties of metals. covering.

Key words: corrosion, ferromagnetic domains, Lorentz's force, an anticorrosive

\section{ОБ ОДНОМ СПОСОБЕ НАНЕСЕНИЯ АНТИКОРРОЗИОННОГО ПОКРЫТИЯ НА ВНУТРЕННЮЮ ПОВЕРХНОСТЬ ТРУБ}

$\begin{aligned} & \text { Аннотация: } \text { в статье приведен краткий анализ способов нанесения } \\ & \text { антикоррозионных } \text { покрытий на металльи и предложен способ нанесения } \\ & \text { антикоррозионного } \text { покрытия на внутреннюю поверхность труб с учетом }\end{aligned}$
ферромагнитных свойств металлов.

Ключевые слова: коррозия, ферромагнитные домены, сила Лоренца, антикоррозионное покрытие.

В настоящее время острой проблемой нефтегазодобывающей отрасли стали аварии промысловых трубопроводов. Одна из основных причин аварий - коррозия металлов.

На крупнейших нефтегазовых месторождениях Казахстана, как Кашаган, Тенгиз, Карачаганак предусмотрены технологии поддержания пластового давления с помощью закачки в пласт сухих сернистых газов, добываемых с нефтью на этих месторождениях. В обводненных старых месторождениях, где объемы добычи нефти с каждым годом уменьшаются, поддержания пластового давления производиться путем закачки в пласт воды. С увеличением срока эксплуатации месторождений возрастает объем добываемой минерализованной воды, закачанной в пласт для поддержания пластового давления. Это присуще старым месторождениям нефти и газа в Атырауской и Мангистауской областях. При этих процессах и мероприятиях возрастает опасность 
внутренней коррозии трубопроводов, резервуаров и другого оборудования. Задача осложняется в связи с ростом металлофонда нефтедобывающих предприятий, интенсификацией процессов добычи нефти и попутно добываемой пластовой воды. Соответственно увеличиваются потери металла из-за коррозии.

По информации «Гринпис», на нефтепромысловых трубопроводах происходит около 30-50 тыс. аварий в год, которые приводят к разливу 10-20 млн. тонн нефти. При этом около 90 \% аварий происходит по причине коррозионного поражения материала труб.

Данные по промысловым трубопроводам месторождений Казахстана не имеются по следующим причинам: не функционирование в нашей стране организации по мониторингу технического состояния промысловых трубопроводов; скрытие фактов отказов и аварии от контролируемых органов; хозяевами многих месторождений нефти и газа являются частные или иностранные инвесторы, которые полностью не отчитываются перед властями. Этот факт не дает право рассуждать, что в нашей стране не происходят отказы и аварии промысловых трубопроводов из-за коррозии. Они происходят часто, и это большая проблема.

Учитывая это, в работе предложены результаты исследований и способ по защите от коррозии внутренних стенок промысловых трубопроводов, используемых в нефтегазовой отрасли.

Предлагаемый способ [1] относится к строительству и ремонту объектов добычи, транспортировки, переработки и хранения нефти, газа и воды и может быть использовано при защите от внутренней коррозии трубопроводов в различных отраслях промышленности.

К наиболее распространенным способам защиты трубопроводов от внутренней коррозии относятся: технологические мероприятия, ингибиторная защита, применение коррозионностойких труб, применение защитных покрытий. Однако у всех этих способов и методов кроме достоинств есть и недостатки, которые определяют использование одного из них. Остановимся на некоторые из них.

Известен способ нанесения антикоррозионного покрытия на металлическую поверхность [2], включающий обработку металлической поверхности вращающейся упругой щеткой. Материал покрытия (металл) при взаимодействии с ворсом щетки плавится и в виде капель переносится на обрабатываемую поверхность. Упрочненная таким образом металлическая поверхность обладает большей стойкостью к атмосферной коррозии.

Также известен способ нанесения антикоррозионного покрытия на металл, включающий подачу на его поверхность материала антикоррозийного покрытия и обработку ее вращающимся рабочим органом, где подачу материала антикоррозийного покрытия на поверхность металла осуществляют в твердом виде, а в качестве рабочего органа используется шлифовальный круг и материала антикоррозийного покрытия используют стекло, пластмассу или металл [3].

Недостатком данных способов являются повышенная энергоемкость из-за необходимости расплавления материала покрытия или из-за энергозатраты на вращения шлифовального круга, низкое качество антикоррозионного покрытия и повышенную опасность, связанную с разлетанием металла при вращении щетки и шлифовального круга.

Известен способ восстановительного ремонта и подготовки к эксплуатации нарезных нефтегазопромысловых труб и передвижной комплекс для его осуществления, содержащий первоначальную подготовку к ремонту труб, их разбраковку и очистку, неразрушающий контроль тела труб и их резьбовых элементов, ремонт, гидравлические испытания труб, нанесение на трубные резьбовые элементы антизадирное покрытие, очистку внутренней поверхности труб и нанесение на нее 
антикоррозионное покрытие с последующей сушкой, маркировку и комплектацию в трубные колонны. Ремонт проводят путем ультразвукового восстановления, для чего после контроля качества резьбовых элементов единый технологический поток труб распределяют на два технологических ручья, при этом гидроиспытания труб совмещают с неразрушающим контролем тела трубы методом акустической эмиссии, а между ультразвуковой обработкой резьбовых элементов и нанесением антизадирного покрытия на трубный резьбовой элемент каждой из труб выдерживают время, меньшее периода релаксации металла на контактных поверхностях резьб [4].

Недостатком данного способа является сложная последовательность технологического процесса, оборудование и переоборудование его различными дополнительными устройствами и средствами. Это приводит к сложности конструкции устройства и большим материальным затратам.

Недостатком всех выше указанных способов является не учет того факта, что стальные конструкции являются ферромагнитными материалами, в которых в нормальных условиях существуют доменные структуры. Тем не менее, имеются изобретения, основанные на магнитной обработке технологических жидкостей, которые применяются для снижения коррозии внутренней поверхности трубопроводов технологических жидкостей в разных отраслях.

Известен способ обработки коррозионной среды, включающий воздействие на среду магнитным и электрическим полями и создание градиента концентрации ионов. Электрическое поле индуцируют магнитным полем. Вектор магнитной индукции магнитного поля перпендикулярен вектору скорости потока среды. Индуцируемое электрическое поле перемещает ионы-деполяризаторы в направлении от коррозирующей поверхности. Технический результат заключается в снижении скорости коррозии металла трубопроводов за счет минимизации катодных процессов деполяризации, способствующих коррозии металла [5].

Недостатком данного и тому подобных [6] способов является недостаточный учет ферромагнитных свойств металла труб, постоянное использование электроэнергии, контроль состава коррозионной среды, который влечет за собой постоянное регулирования обработки магнитными и электрическими полями. Это приводит к сложности конструкции устройства и постоянным материальным затратам.

Задачей исследования является разработка способа нанесения антикоррозионного покрытия на внутреннюю поверхность труб с учетом влияния ферромагнитных свойств металла труб, с целью повышения их долговечности.

Известно, что механизм развития коррозии играет важную роль при разработке способов и методов защиты от коррозии стальных конструкций. Учет ферромагнитных свойств стальных конструкций дает возможность пересмотреть механизм развития коррозии [7] и предложить более эффективные методы защиты от коррозии. Механизм заключается в следующем.

Адсорбция коррозионно-активных веществ из среды влияет на уменьшение сродство поверхностных атомов поверхностей стальных конструкций. Под действием различных нагрузок и ударов на ослабленных адсорбцией поверхностях стальных конструкций появляются трещины.

Элементы стальных конструкций являются ферромагнитными материалами, состоящие из доменных структур [8]. В свою очередь, появившиеся трещины и дефекты повреждают доменные структуры в ферромагнитных материалах, в которых при повреждении изменяются магнитные характеристики.

При нарушении доменной структуры стали, происходит разделение доменов на части (рис.1), из-за этого в концах трещин начинают создаваться магнитные полюса [9], а между ними действовать магнитное поле. 
Как известно [10], на заряды движущихся в магнитном поле, созданном от нарушенных структур ферромагнитных доменов, то есть между краями трещин, действует сила Лоренца, описываемая по формуле

$$
\vec{F}_{J}=q \cdot[\vec{v} \cdot \vec{B}]
$$

В обычной водной среде присутствуют молекулы воды $\mathrm{H}_{2} \mathrm{O}$, ионы гидроксония $\mathrm{H}_{3} \mathrm{O}^{+}$и гидроксила $\mathrm{OH}^{-}$. Перемещение ионов в воде происходит по особому, так называемому эстафетному механизму [11], который состоит в том, что между ионами гидроксония $\mathrm{H}_{3} \mathrm{O}^{+}$и молекулами воды, а также между молекулами воды и ионами $\mathrm{OH}^{-}$ непрерывно происходит обмен ионами водорода $\mathrm{H}^{+}$. Под действием силы Лоренца [12] происходит разделение ионов с разными знаками, это способствуют дополнительному появлению между краями трещин ионов водорода $\mathrm{H}^{+}$и гидроксил-ионов $\mathrm{OH}^{-}$, то есть диссоциации воды.

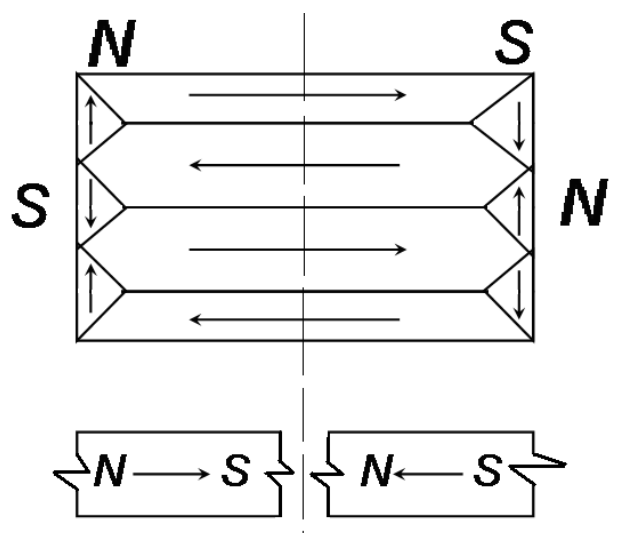

\section{Рисунок 1 - Схема разрушения доменной структуры}

Кроме этого, сила Лоренца играет важную роль при абсорбции частиц из водной среды. Особенно, интенсивно будут поглощаться трещинами положительные ионы по направлению силы Лоренца. На ионы $q$ движущиеся с определенной скоростью $v$ в магнитном поле $B$ действует сила Лоренца $F_{Л}$, которая старается повернуть ионы в перпендикулярном направлении (рис.2). За счет силы Лоренца действующем в этом магнитном поле ионы водорода $\mathrm{H}^{+}$и гидроксил-ионы $\mathrm{OH}^{-}$будут притягиваться к краям трещины как к полюсам магнита (рис.3).

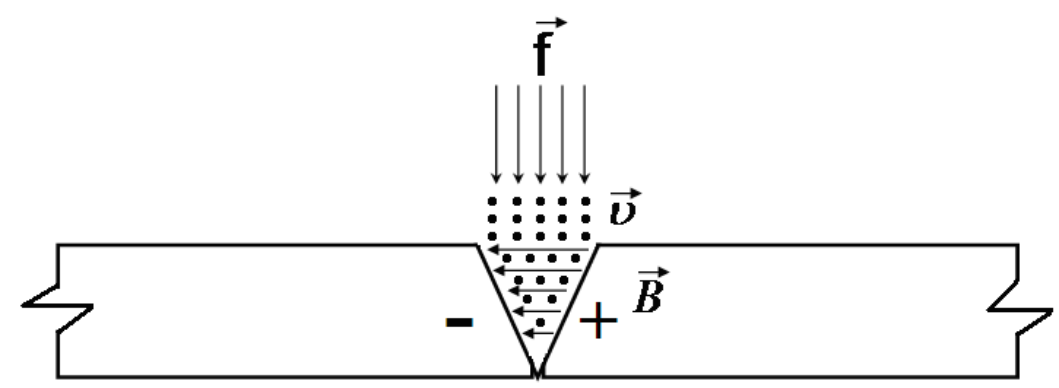

Рисунок 2 - Направления силы Лоренца, скорости движения ионов и магнитного поле касательно трещины в доменной структуре 


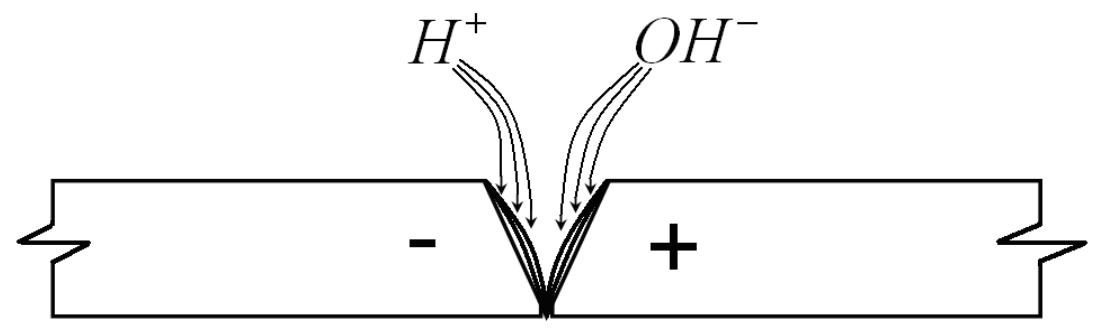

\section{Рисунок 3 - Наполнение трещины доменной структуры ионами $\mathrm{H}^{+}$и $\mathrm{OH}^{-}$}

После прохождения физического процесса начинается химический процесс, т. е. реализуется этап развития трещин - их коррозионное зарождение. В трещине из-за недостатка кислорода активно протекает реакция

$$
\mathrm{Fe} \rightarrow \mathrm{Fe}^{2+}+2 \mathrm{e}^{-} ; \mathrm{Fe}^{2+}+2 \mathrm{OH}^{-} \rightarrow \mathrm{Fe}(\mathrm{OH})_{2} ; 2 \mathrm{H}^{+}+2 \mathrm{e}^{-} \rightarrow \mathrm{H}_{2},
$$

В результате химической реакции образуется гидроксид железа (II), который создает пленку. Она наполняет образовавшиеся трещины (рис.4), что приводит к замедлению или завершению выше приведенных физических и химических процессов, то есть к пассивации металла. Также, в данном случае активно восстанавливается и абсорбируется водород. За счет силы Лоренца к вершине трещины сильно притягиваются и абсорбируются только ионы водорода $\mathrm{H}^{+}$, так как они имеют положительный заряд $q$ ионов.

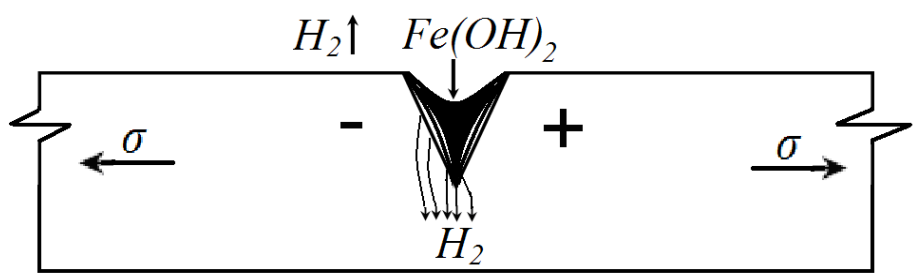

\section{Рисунок 4 - Образованная пленка из гидроксида железа (II) в трещине и восстановление ионов водорода}

В трещине ионы водорода $\mathrm{H}^{+}$восстанавливаются, и по двум схемам удаляются из трещины, то есть часть абсорбируется в структуру металла через вершину трещины, а остальная часть удаляется как газ в атмосферу:

$$
\begin{aligned}
4 \mathrm{H}^{+}+4 \mathrm{e} \rightarrow & \rightarrow \mathrm{H}_{2} \uparrow \text { (в атмосферу) } \\
& \rightarrow 2 \mathrm{H} \text { (абсорбируется металлом) }
\end{aligned}
$$

Часть водорода, попавшая в металл, диффундирует по его объему в зону максимальных трехосных напряжений, которая находится перед вершиной трещины. Поступивший в эту зону водород, ускоряет процесс коррозионного подрастания трещины, так как наводороживание металла существенно снижает его коррозионную стойкость (рис.4).

На внешней поверхности оксидной пленки, доступной растворенному кислороду в воде, гидроксид железа (II) окисляется до гидроксида железа (III):

$$
4 \mathrm{Fe}(\mathrm{OH})_{2}+2 \mathrm{H}_{2} \mathrm{O}+\mathrm{O}_{2} \rightarrow 4 \mathrm{Fe}(\mathrm{OH})_{3}
$$


В дальнейшем происходит частичная дегидратация гидроксида железа (III). Данная реакция описана в следующей формуле:

$$
\mathrm{Fe}(\mathrm{OH})_{3}-\mathrm{H}_{2} \mathrm{O} \rightarrow \mathrm{FeO}(\mathrm{OH})
$$

Стальные конструкции работают в постоянных условиях переменных нагрузок (напряжений). При малейшем механическом воздействии - увеличение величин механических напряжении или простое механическое воздействии на элементы стальных конструкций, ранее отмеченные трещины раскрываются, и возобновляется процесс коррозии. Требуется, чтобы даже при образованных трещинах защитные покрытия сохраняли металл от коррозии.

Учитывая вышесказанное, в нами предложен следующий способ нанесения антикоррозионного покрытия на внутреннюю поверхность труб (рис.5):

- перед тем как на внутреннюю поверхность трубы наносится покрытие, определяем по опыту эксплуатации данной трубы его напряженно-деформированную работу и дефектные участки;

- крепко закрепляем трубу 5 на лежак для труб;

- с одной стороны трубы заглушаем неподвижной опрессовочной головкой 6 , а с другой стороны подвижной опрессовочной заглушкой 4;

- соединяем к подвижной опрессовочной заглушке подводящие 2 и отводящие 7 патрубки, которые соединены к насосной установке 1, развивающий высокий напор;

- в качестве материала антикоррозийного покрытия используем силикатно-эмалевые, полимерные или комбинированные покрытия;

- подводящие и отводящие патрубки имеют шаровые клапаны 3;

- включаем насос, который подает антикоррозионное покрытие в подводящий патрубок с давлением выше на 25-30\% от рабочего давления трубы;

- от избыточного давления на внутренней поверхности трубы должны раскрыться трещины, неоднородности, дефекты и другие повреждения;

- при удержании давлении в данном состоянии, антикоррозионное покрытие тщательно наносится на внутреннюю поверхность трубы, заполняя покрытием все образованные трещины и дефекты;

- процесс продолжается определенное время, которое зависит от свойств трубы и антикоррозионного покрытия;

- высушиваем трубу в соответствии со всеми требованиями;

- проверяем качество покрытия и при необходимости опять повторяем вышеуказанные мероприятия.

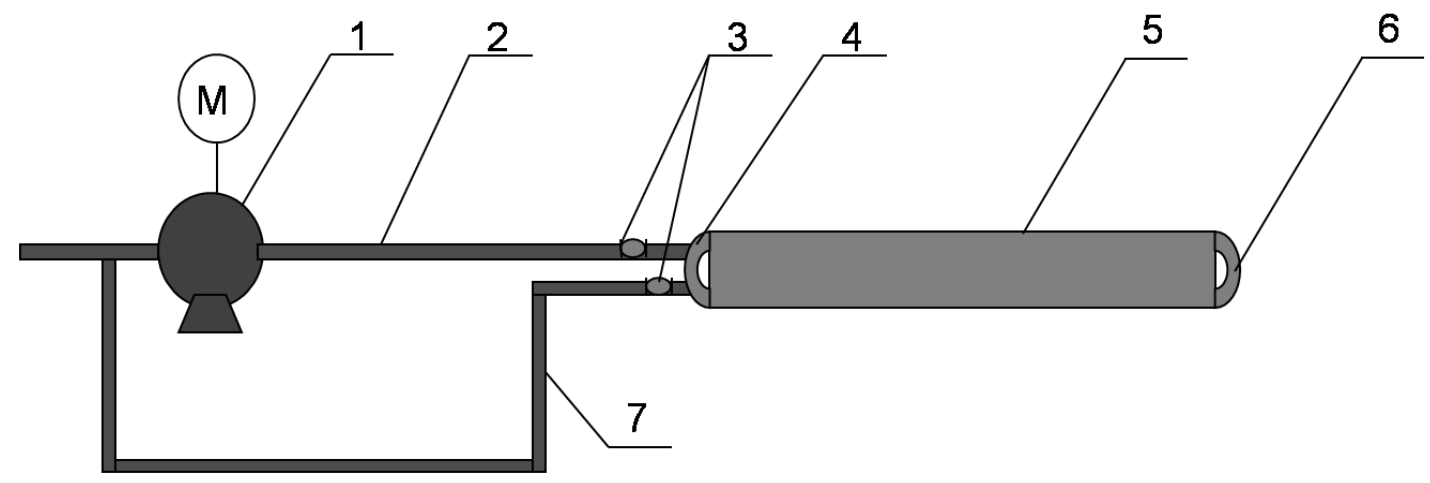

Рисунок 5 - Предлагаемая схема нанесения антикоррозионного покрытия на внутреннюю поверхность труб 
Предложенный способ легко реализуем в промышленных условиях, поскольку для его реализации требуется стандартное оборудование.

При выполнении этих мероприятий по нанесению антикоррозионного покрытия, образованные трещины и дефекты будут заполнены покрытием, это не позволит адсорбироваться агрессивным веществам из транспортируемой жидкости, которые способствуют интенсивной коррозии внутренней стенки труб.

\section{References:}

1. Алимбаев Б.А., Манапбаев Б.Ж. Инновационный патент РК №27327. Способ нанесения антикоррозионного покрытия на внутреннюю поверхность труб / Бюллетень №9 РГКП «Национальный институт интеллектуальной собственности», Астана.Опубл. 16.09.2013.

2. a.c. СССР № 1206068 , В 24 В 39/00, от 1986. Способ нанесения покрытия на металлическую поверхность.

3. Мравян К.П., Шахов В.В. Патент № 2167219, С23С26/00 от 20.05.2001. Способ нанесения антикоррозионного покрытия на металл.

4. Калинин О.Б., Родзянко Е.Д., Маркин В.А., Чебанов В.Б., Новичков А.А. Патент № 000285, B23P 6/00, B23Q 41/00 от 25.06.1998. Способ восстановительного ремонта и подготовки к эксплуатации нарезных нефтегазопромысловых труб и передвижной комплекс для его осуществления.

5. Лаптев А.Б., Навалихин Г.П., Цыпышев О.Ю. Патент № 2293707, C02F 1/48 от 20.02.2007. Способ обработки потока коррозионной среды.

6. Лаптев А.Б. Патент № 2287492, С02F 1/48 от 20.11.2006. Способ обработки потока технологической жидкости и устройство для его осуществления.

7. Алимбаев Б.А., Манапбаев Б.Ж. Развитие коррозии в элементах металлических конструкций в водной среде. - Тараз: Тараз университеті, 2012.-136 с.

8. Акулов Н.С. Ферромагнетизм. - М.-Л.: Госиздат. технической и теоретической литературы, 1939.

9. Гораздовский Т.Я. Неразрушающий контроль.- М.: Знание, 1977.- 64 с.

10. Савельев И.В. Курс общей физики. Электричество. - М.: Наука, 1970. - Т.2. - 432 c.

11. Стромберг А.Г., Семченко Д.П. Физическая химия. Учеб. для хим. спец. вузов. Под редакцией А.Г.Стромберга. - 4-е изд. испр. - М.: Высш. шк., 2001. - 527 с.

12. Брановер Г.Г., Цинобер А.Б. Магнитная гидродинамика несжимаемых сред. М.: Главная редакция физико-математической литературы издательства «Наука», 1970. - 380 с. 